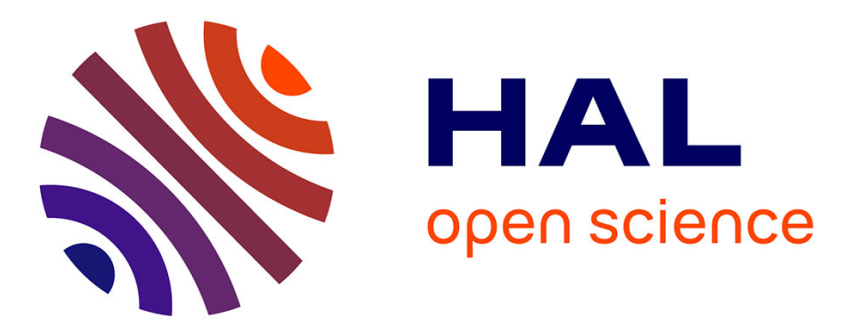

\title{
Comparison between experimental tests and numerical simulations carried out on a tensegrity minigrid
}

\author{
Jean-François Dubé, Nicolas Angellier, Bernard Crosnier
}

\section{To cite this version:}

Jean-François Dubé, Nicolas Angellier, Bernard Crosnier. Comparison between experimental tests and numerical simulations carried out on a tensegrity minigrid. Engineering Structures, 2008, 30, pp.1905-1912. 10.1016/j.engstruct.2007.12.010 . hal-00359400

\section{HAL Id: hal-00359400 \\ https://hal.science/hal-00359400}

Submitted on 16 Feb 2009

HAL is a multi-disciplinary open access archive for the deposit and dissemination of scientific research documents, whether they are published or not. The documents may come from teaching and research institutions in France or abroad, or from public or private research centers.
L'archive ouverte pluridisciplinaire HAL, est destinée au dépôt et à la diffusion de documents scientifiques de niveau recherche, publiés ou non, émanant des établissements d'enseignement et de recherche français ou étrangers, des laboratoires publics ou privés. 


\title{
COMPARISON BETWEEN EXPERIMENTAL TESTS AND NUMERICAL SIMULATIONS CARRIED OUT ON A TENSEGRITY MINI GRID
}

Jean François DUBE, Nicolas ANGELLIER, Bernard CROSNIER

Laboratoire de Mécanique et Génie Civil - UMR5508, Montpellier University, cc048, Place E. Bataillon, 34095 Montpellier cedex 5, France

E-mail:_dube@lmgc.univ-montp2.fr, angellier@lmgc.univ-montp2.fr.crosnier@lmgc.univ-montp2.fr

\begin{abstract}
Tensegrity systems are structures in equilibrium under an initial self-stress state. This self-stress state is composed of elementary self-stress states, which constitute its basis. They have complex behaviour and the self-stress state can be modified by external loads. A continuous dialogue between numerical simulations and experimental tests made it possible to validate previous models. In this paper, we checked the validity of the indirect methods currently used to measure cable tension. We show that the connection between elements is embedding in spite of an apparent freedom movement of the structure. We show the necessity to use structural beam elements to correctly describe the bars behaviour in the structure.

Static and vibratory measurements show the importance of the bending moment for the elements. We here improve the modelling of the behaviour of the Tensarch ${ }^{\circledR}$ project tensegrity grid.
\end{abstract}

Keyword: tensegrity, self-stress state, vibration, measure, EF model.

\section{INTRODUCTION}


The Design and Structures group in Montpellier has been involved in tensegrity structure testing for a number of years [1,2]. J. Averseng [3, 4] demonstrated the feasibility of this approach, but to carry out reliable and relevant tests, the state and behaviour of the tested structure must be thoroughly understood. It is difficult to calculate the stress state of the elements in a structure without using cumbersome means of measurement $[4,5]$. Thus our approach here is to link easily accessible measurements to real stress states $[6,7,8]$. Stress states are evaluated by the vibratory measurement of several vertical ties. The stresses in the elements are then deduced using a bench-top calibrated force-frequency law. However, the stress state deduced from these measurements does not comply with the overall load bending behaviour simulated with our computation code.

This raises several questions. Are force-frequency laws relevant to the elements in the structure? Is it realistic to use a bar behaviour of the different elements? To answer these questions we performed a complete measurement programme on a tensegrity structure. We also checked the influence of the type of component used on the behaviour of the structure.

Our team has had a tensegrity structure available for experiments since the year 2000 , following the Tensarch ${ }^{\circledR}$ project [9]. This project focused on the feasibility of the design and creation of a flat tensegrity grid measuring $12.80 \mathrm{~m} \times 6.40 \mathrm{~m}$. For our purposes, one eighth of this grid was used, which we refer to as a mini grid.

\section{NUMERICAL STUDY OF THE MINI GRID}


Mini grid

This is a double layer plane grid of cables the basic pattern of which uses the expander principle: two by two, the struts form perpendicular, opposing V's, separated by a vertical tie the length of which can be made to vary (figure 1).

This consists of 81 components linked by nodes: 24 compressed struts (tubes) and tensioned elements, i.e., 36 cables in addition to 9 vertical ties and 12 peripheral ties (table 1); the ties are the active components of the structure $[10,11]$ (figure 2).

\section{Self-stress state}

System equilibrium is obtained when all nodes are in equilibrium. The static equilibrium of a node $i$ is written as:

$$
\sum_{j \neq i} T_{i j}+F_{i}=0
$$

$T_{i j}$ is the internal force vector of the element linking node $j$ to node $i$, and $F_{i}$ is the external force vector directly applied to node $i$. The internal forces $T_{i j}$ are a function of the deformation of each element; $x_{i}, y_{i}, z_{i}$ are spatial co-ordinates of node $i$, and $l_{i j}^{0}$ the length of the element connecting nodes $i$ and $j$ in the reference configuration. The projection of equation 1 on three axes gives:

$$
\begin{aligned}
& \sum_{j \neq i} T_{i j} \frac{x_{j}-x_{i}}{l_{i j}^{0}}+F_{i}^{x}=0 \\
& \sum_{j \neq i} T_{i j} \frac{y_{j}-y_{i}}{l_{i j}^{0}}+F_{i}^{y}=0 \\
& \sum_{j \neq i} T_{i j} \frac{z_{j}-z_{i}}{l_{i j}^{0}}+F_{i}^{z}=0
\end{aligned}
$$


$T_{i j}$ is the algebraic expression of the force in element $(i, j)$, connecting node $\mathrm{i}$ and node $\mathrm{j}$. This equilibrium equation can be simplified by introducing the force density $q_{i j}$ of each element $(i, j)[12]$ :

$$
q_{i j}=\frac{T_{i j}}{l_{i j}^{0}}
$$

The relation for one node (2) then becomes:

$$
\begin{aligned}
& \sum_{j \neq i} q_{i j}\left(x_{j}-x_{i}\right)+F_{i}^{x}=0 \\
& \sum_{j \neq i} q_{i j}\left(y_{j}-y_{i}\right)+F_{i}^{y}=0 \\
& \sum_{j \neq i} q_{i j}\left(z_{j}-z_{i}\right)+F_{i}^{z}=0
\end{aligned}
$$

The system of equations obtained by applying the equations in (4) to all the nodes of the structure is:

$$
\mathbf{A q}=\mathbf{f}
$$

with $\mathbf{A}$ for the equilibrium matrix of the structure (dimension $b \times 3 n$ ), $\mathbf{q}$ for the vector describing the force densities in elements $b$, and $\mathrm{f}$ for the vector of the external forces acting on nodes $n$. Self-stress ensures the stability and the rigidity of the tensegrity system. Self-stress is then the whole set of internal forces occurring in the initial state, without external loading. This state of equilibrium corresponds to a field of force densities $\mathbf{q}_{0}$ satisfying:

$$
\mathbf{A q _ { 0 }}=\mathbf{0} \Leftrightarrow \mathbf{q}_{\mathbf{0}} \in \operatorname{ker} \mathbf{A}
$$

The selfstress state can be expressed on the basis of the subspace ker $\mathbf{A}$, also noted as $\mathbf{S}$, which is composed of several fundamental self-stress states. Numerical techniques 
are developed to accurately determine the self-stress basis. Direct determination of the fundamental self-stress states, starting from kernel A, poses numerical problems which are addressed by Quirant [13]. Pellegrino and Calladine have developed methods to determine selfstress states and their internal mechanisms (finite or infinitesimal [14]) on the basis of a study of the equilibrium matrix of a given system. Vassart suggests using the transposed matrix $\mathbf{A}^{\mathrm{T}}$ and the displacement field instead of the force field [12] to determine the elastic potential criterion corresponding to stable equilibrium. The selfstress basis $\mathbf{S}$ resulting from kernel $\mathbf{A}$ cannot be used directly, since the equilibrium matrix A does not take into account the unilateral behaviour of elements. Every selfstress state which meets the unilaterality conditions for tensioned members is called "conform". A conform selfstress state can result from a linear combination of several conform states [15], or directly from linear combination of the elements defining subspace ker $\mathbf{A}$, or $\mathbf{S}[16]$ :

$$
\mathbf{q}_{0}=\mathbf{S} \boldsymbol{\alpha}
$$

The components of the $\alpha$ vector are chosen to satisfy stress conditions for members. In our laboratory, the fundamental selfstress states are determined by using a dedicated code (Tensegrité2000, [13]).

\section{Minigrid selfstress state}

Tenségrité2000 software is able to determine the basic self-stress states and mechanisms of a structure starting from geometry and boundary conditions. Basic self- 
stress states are states which gives elementary stabilities of the structure. The combination of these states makes it possible to ensure stability and to respect the threshold behaviour of the elements. The bars should not reach the buckling load and the ties should not break. With three non-symmetrically support conditions it has only two basic self-stress states (noted EA1 and EA2). These are the states from which a selfstress state can be built, ensuring the stability of the structure and the boundary operating states applied. A ratio of 0.5 between the two coefficients $a$ and $b$ of each basic self-stress state $\left(a^{*} \mathrm{EA} 1+b^{*} \mathrm{EA} 2\right)$ provides the most homogeneous distribution of forces possible in the components, particularly for cable tensions (figure 3).

On the basis of this choice of self-stress state and support conditions, the finite element code Cast3M [17] is used for more advanced numerical simulations. Bearing in mind future experimental objectives, the study focused on establishing normal modal frequencies and their evolution according to self-stress level. The first frequency mode is proportional to the square root of the tension of the element linked to self-stress level (figure 4). For the following modes, evolution is quasi linear and weak.

\section{From simulation to experiment}

The preliminary numerical study of the mini grid provided an indication of the real mechanical behaviour of the structure. This study also clarified the choices to be made particularly for support conditions. Nevertheless, it is clearly important to focus on carefully setting the self-stress state. A method had already been developed in the laboratory to obtain a target self-stress state from a structure's real state [11]. 
Measurement of the real state relies on the vibrating wire method applied to the tensioned components in the mini grid. We propose here more direct and complete measurements. The strut and tie components were instrumented with strain gauges. For cable tension, the results were obtained using a three-point tensiometer developed in the laboratory. The purpose of these measurements is to verify the relevance of indirect measurements and refine identification of the real state.

\section{MINI GRID INSTRUMENTATION}

Strain in struts and ties

The wish to explore a new approach in the measurement of strain in the mini grid components was not merely based on using more direct methods. Indeed the use of gauges (Vishay CEA-06-250UW-350) made it possible to estimate strain in the compressed struts, components that were hitherto non-instrumented. To do so, the gauge mountings were carefully selected. Thus, for the struts, a complete standard bridge mounting was devoted to detect bending, while a mounting known as a complete half-bridge measured compression, free of bending. This mounting consists of a complete bridge that functions like a half bridge when resistances are used instead of gauges on the two opposing arms of the bridge. The same mounting is used to obtain the tension of the ties, on the assumption that bending does not important. Not all components of the mini grid could be instrumented. As the conditioner paths were limited in number (Vishay 2120) we adopted a strategy that took account of the selfstress states of the mini grid in addition to its geometrical symmetries (figure 5a). Ties 
TV1, TV2, TV3, TP1 and TP2 are equipped to measure traction force. Strut B1, B2, B3, B4 are equipped to measure compression force in the medium of the strut and the bending moment at the end.

Traction-compression calibrations were carried out using a force transducer: the ties were calibrated on a traction bench, while the struts were calibrated by direct loading. Figure $5 \mathrm{~b}$ shows how in the case of struts, the values obtained using the extensometric method closely agree with those of the force transducer (differences inferior to $3 \%$ ). The same is true for the gauge mountings on the ties.

Integrating the equipped components into the tensegrity structure allayed suspicions of strut bending and allowed node compensation to be checked (table 2). The structure is not loaded but has its selfstress state. Vertically, strut compression is seen to be almost perfectly compensated by the tension in the tie. The same is true horizontally with cable tension in the strut plane. For the two other cables, variance does not exceed $15 \%$. For these strut force levels a bending moment of 25.4 daN.m was obtained at the end of the strut. Normal strain thus generates a relative deformation of $1.21 \%$, whereas bending generates a relative deformation variation of $0.13 \%$ between the extreme strut fibres.

\section{Static loading}

The mini grid is loaded by applying masses to the peripheral nodes of the lower layer (figure 6). The masses applied were $2 \mathrm{~kg}, 6 \mathrm{~kg}, 14.7 \mathrm{~kg}, 23.4 \mathrm{~kg}$ and $32.1 \mathrm{~kg}$. Using a tacheometer, we measured the displacement field of the nodes of the upper layer (figure 
6). The nodes of the two layers were not superimposed. A general weak self-stress state is imposed on the structure. The self-stress state coefficients identified by measurements of the forces were $a=1722$ and $b=3801$. This weak self-stress state permitted a flexible structure with notable displacements. Two types of simulations of the behaviour were carried out: one using a structural bar behaviour for all elements, the other using structural beam behaviour for the bars. Bar element cannot support forces orthogonal and moments. Beam element is based on Euler-Bernoulli beam theory. Ties and cables are described by 10 bar elements, struts are described by 5 beam elements. Figure 7 shows that for two points of measurement the behaviour beam is more adapted to describe the behaviour of the mini grid. We calculate the quadratic mean displacement error for the four loads. Figure $8 \mathrm{a}$ is the result when we used bar elements for the struts. Figure $8 \mathrm{~b}$ is the result when we used beam elements for the struts. The tests show a linear behaviour whereas modelling bars described nonlinear behaviour. We cannot explain simply the behaviour nonlinear obtained with the bar description for the struts. This result is obtained with tow different codes and struts are always compressed. Modelling beam is not so close to the real behaviour for weak loadings but remains linear.

\section{Vibrating identification}

When a tensioned component is made to vibrate (tie or cable) after a shock, the vibration frequency value can provide an indication of the tension level when the right calibration law is used [17]. To check these, tests were carried out on a tension bench to 
refine the coefficients of the law. We now dispose of the force measurement for the ties, because of the strain gauge mountings, which permit tests with the ties integrated in the mini grid. Measurements were taken at different locations on three vertical ties: the central tie (tie 1), a corner tie (tie 2) and a side tie (tie 3). There is a difference between the calibration carried out on the bench and the measure taken on the tie in the mini grid (figure 9). The characteristics of the vertical ties being identical, the bench conditions are incompatible with those in situ. Furthermore the boundary conditions of the ties in situ appear different for each case. To check this hypothesis, we compared numerical simulations with experimental tests.

With Cast3M code [18], we used the same modelling of the static simulations. We increase the self-stress level. For each tie measured, we applied a dirac loading. The internal force of the tie and the first eigenmode were computed. We calculated the theoretical relation between force and $1^{\text {st }}$ mode for a beam with a restrained support and a hinged bearing. Simulation of the central tie (figure 10) in situ shows that the frequency law coincides with the curve corresponding to completely blocked nodes. The same results were obtained for the peripheral tie (figure 11). These are longer than the central tie, but they have the same behaviour. In these simulations, tension was increased not only in a tie but also in the self-strain level of the whole structure. The struts contribute rigidity in rotation but so do the cables.

\section{CONCLUSIONS}


The aim of this study was to test under natural strain, but the prerequisite for this is a complete understanding of the mechanical behaviour of these structures. In the case of a tensegrity system this chiefly consists of accurately identifying the real self-strain state Ea. We presented the instrument choices used to identify and test the mechanical state of the mini grid: strain gauge mountings to measure compression in the struts and tension in the ties, and the use of a tensiometer for the cables, are a useful addition to the vibrating wire method. The latter in fact is weak in dealing with the diversity and complexity of the support conditions of the components in the mini grid. Furthermore, we showed that compressed elements are subject to a substantial bending moment that blocks the nodes in rotation. The different elements can no longer be assimilated to finite strut elements but must be modelled by finite beam elements.

The next series of trials will consist of studying node displacement fields induced by various static loads, for several self-strain levels in the mini grid.

\section{REFERENCES}

[1] R. Motro, Formes et forces dans les systèmes constructifs cas des systèmes réticulés spatiaux autocontraints, Doctorat d'état de l'Unviversité des Sciences et Techniques du Languedoc, 192p, 1983.

[2] R. Motro, Tensegrity, Kogan Page Science, ISBN : 1903996376, 2003. 
[3] J. Averseng, B. Crosnier, Static and dynamic robust control of tensegrity systems, Journal of the International Association for Shell and Spatial Structures, 2004; 45 (3): 169-174.

[4] J. Averseng, Mise en oeuvre et contrôle des systèmes de tenségrité, Thèse de Doctorat de l'Université Montpellier II, dir. B. Crosnier, J.F. Dubé, 150 p, 2004.

[5] J.F. Dubé, B. Crosnier, Identification of cable slackening by analyzing the temporal response of the structure, Proc. of IASS 2004, Shell and Spatial Structures from Models to Realization, ed. R. Motro; 2004, 134-135, 8p in CDROM.

[6] V. Barcilon, Inverse problem for the vibrating beam in the free-clamped configuration, Philosophical transaction of the Royal Society of London, A Mathematical and Physical Sciences, 1982; A304: 221-251.

[7] V. A. Gotlib, T. Sato, A. I. Beltzer, Neural computing of effective properties of random composite materials, Computers and Structures, 2001; 79: 1-6.

[8] J.H. Lin, X.L. Guo, H. Zhi, W.P. Howson, F.W. Williams, Computer simulation of structural random loading identification, 2001; 79: 375-387.

[9] R. Motro, Tensarch Project. First International Conference on Space Structures. In : Telford T, editor. Guilford, UK : G.A.R. Park and P. Disney; 2002, 57-66.

[10] J. Averseng, Méthodologie de la mise en auto-contrainte des systèmes de tenségrité, DEA, dir. B. Crosnier, M.N. Kazi Aoual, LMGC, Université Montpellier II, 46p, 2001. 
[11] J. Averseng, B. Crosnier, Prestressing tensegrity systems - Application to multiple selfstress state structures, International Journal of Structural Stability and Dynamics, 2004; 4 (4): 543-557.

[12] N. Vassart, Recherche de forme et stabilité des systèmes réticulés autocontraints application aux systèmes de tenségrité, Ph.D. thesis, Université Montpellier 2, 1997.

[13] J. Quirant, Systèmes de tenségrité et autcontrainte : qualification, sensibilité et incidence sur le comportement, Ph.D. thesis, Université Montpellier 2, 2000.

[14] S. Pellegrino and C.R. Calladine, Matrix analysis of statically and kinematically indeterminate frameworks, International Journal of Solids and Structures, 1986; 22: $409-428$.

[15] L. R. Sanchez, Contribution à l'étude mécanique des systèmes de tenségrité, Ph.D. thesis, Université Montpellier 2, 2005.

[16] J. Quirant, M. N. Kazi-Aoual, and R. Motro, Designing tensegrity systems: the case of a double layer grid, Engineering Structures, 2003; 25: 1121-1130.

[17] B. Crosnier, F. Cevaer, Stratégies de mise en précontrainte dans les systèmes de tenségrité et contrôle. Revue Française de Génie Civil, Hermès, 2003 ; 7/3: 311-328.

[18] P. Verpeaux, T. Charras, A. Millard, Castem2000, une approche moderne du calcul des structures. In J.M Fouet, P. Ladevèze, and R. Ohayon, editors, Calcul des structures et intelligence artificielle, Pluralis; 1988, 261-271. 
Figure 1

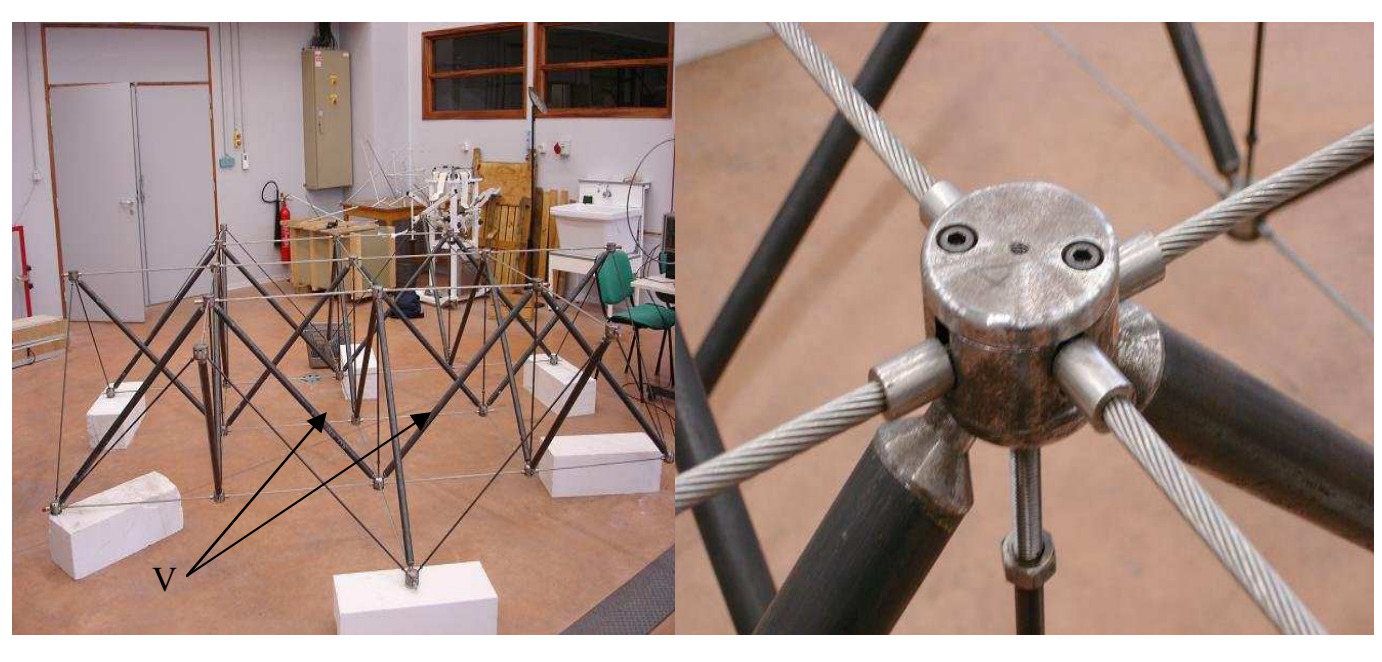

Figure 1. The mini grid: a) general view, b) close up of a node.

(1)

(1)

.

(a)

$\sqrt{10}$ 
Figure 2
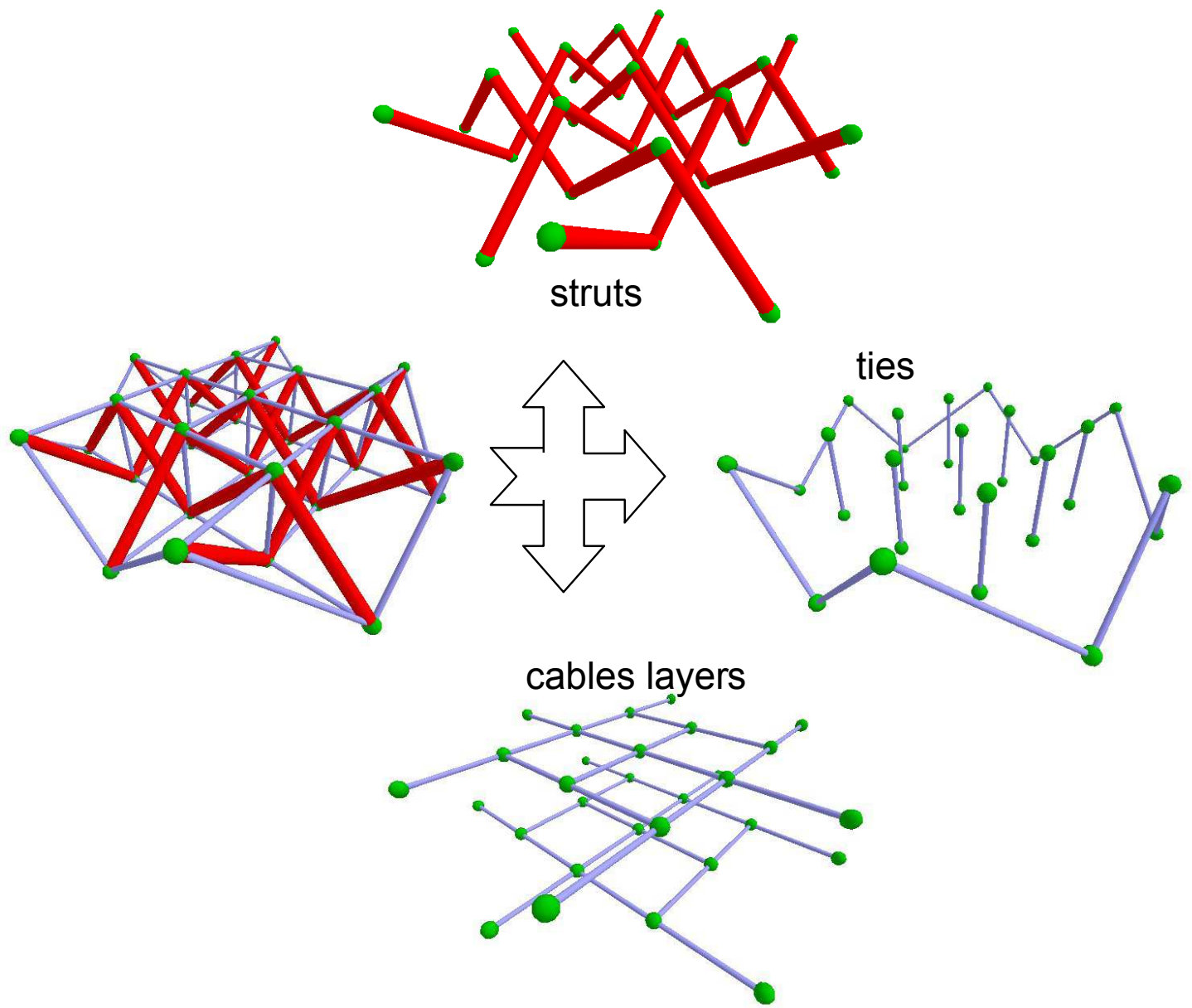

Figure 2. Minigrid decomposition, with struts, ties, cables. 

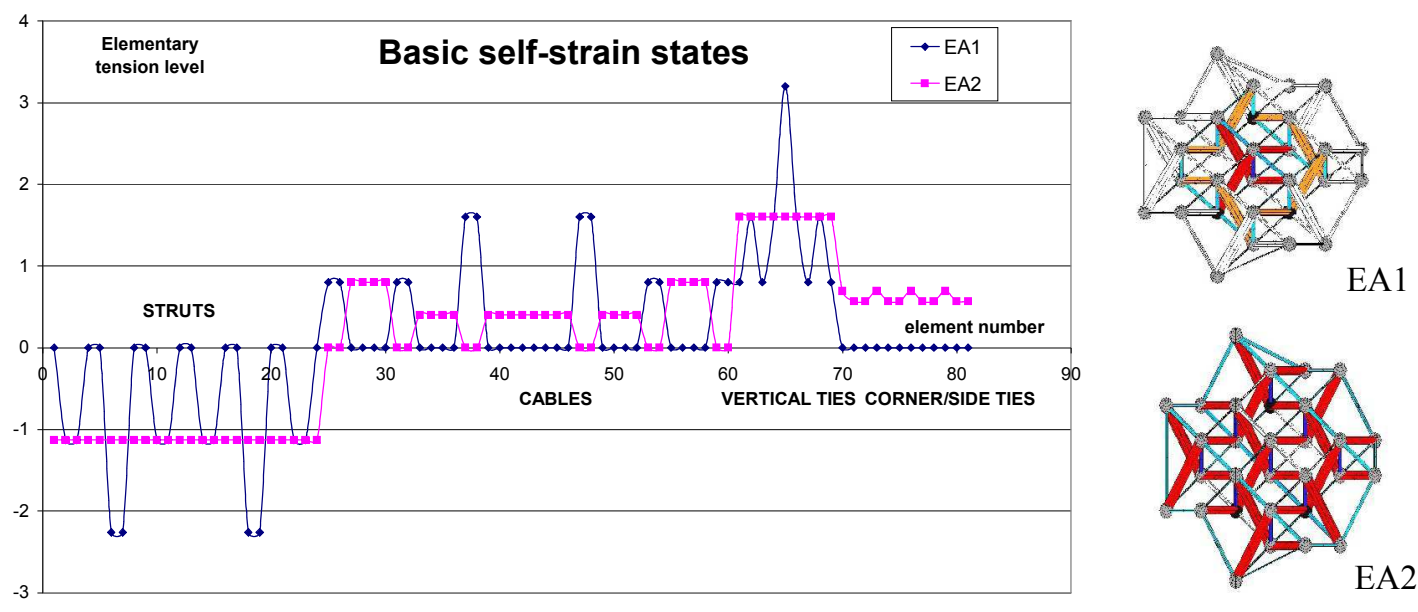

Figure 3. Two basic self-stress states EA1 and EA2 of the mini grid.

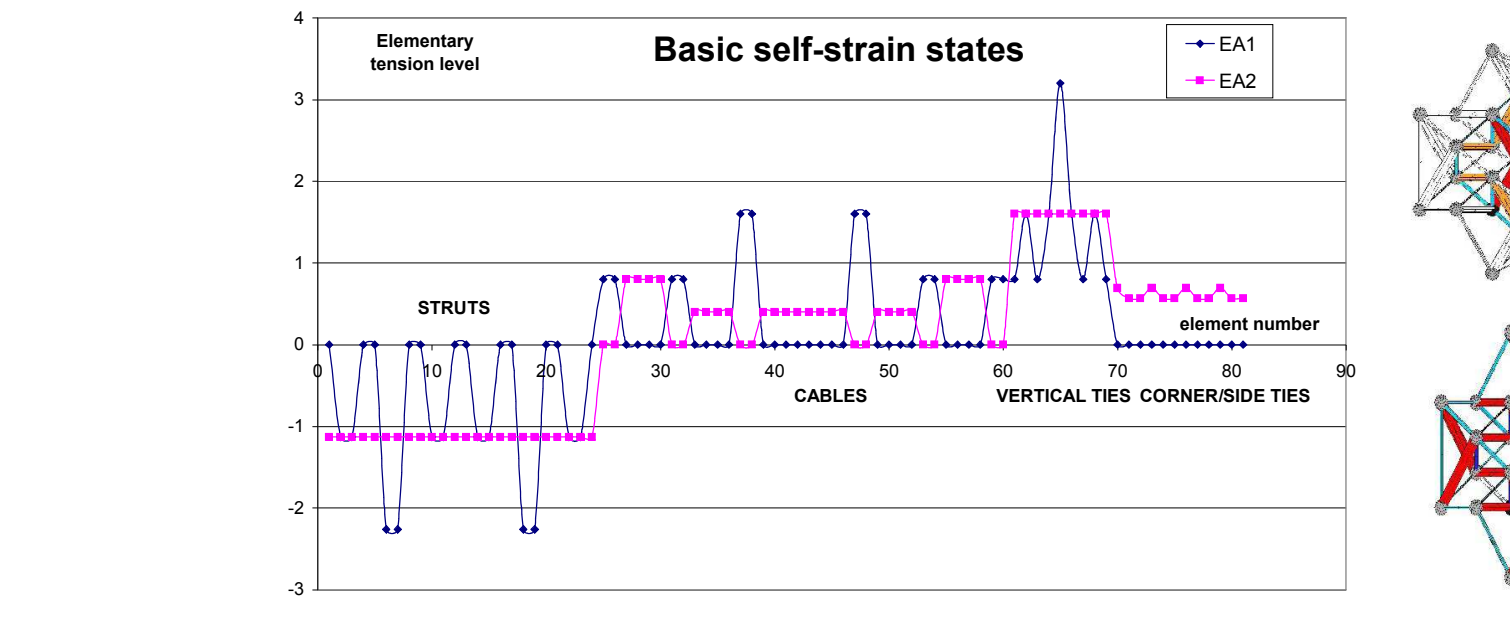

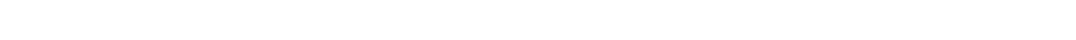

\section{EA2 \\ EA2 \\ IAI}

年



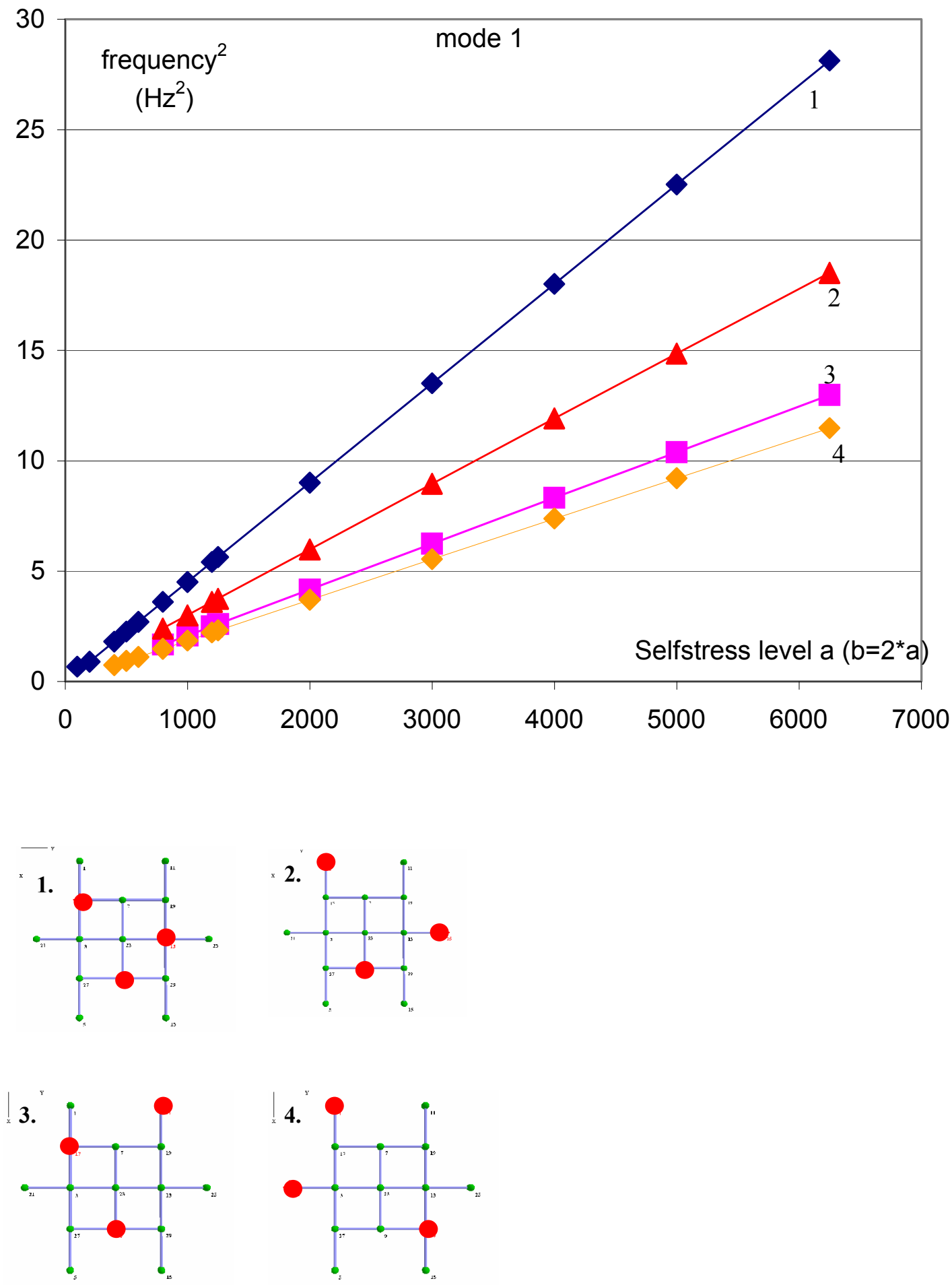

Figure 4. Evolution of the first normal mode frequency according to self-stress level for 4 boundary conditions. 


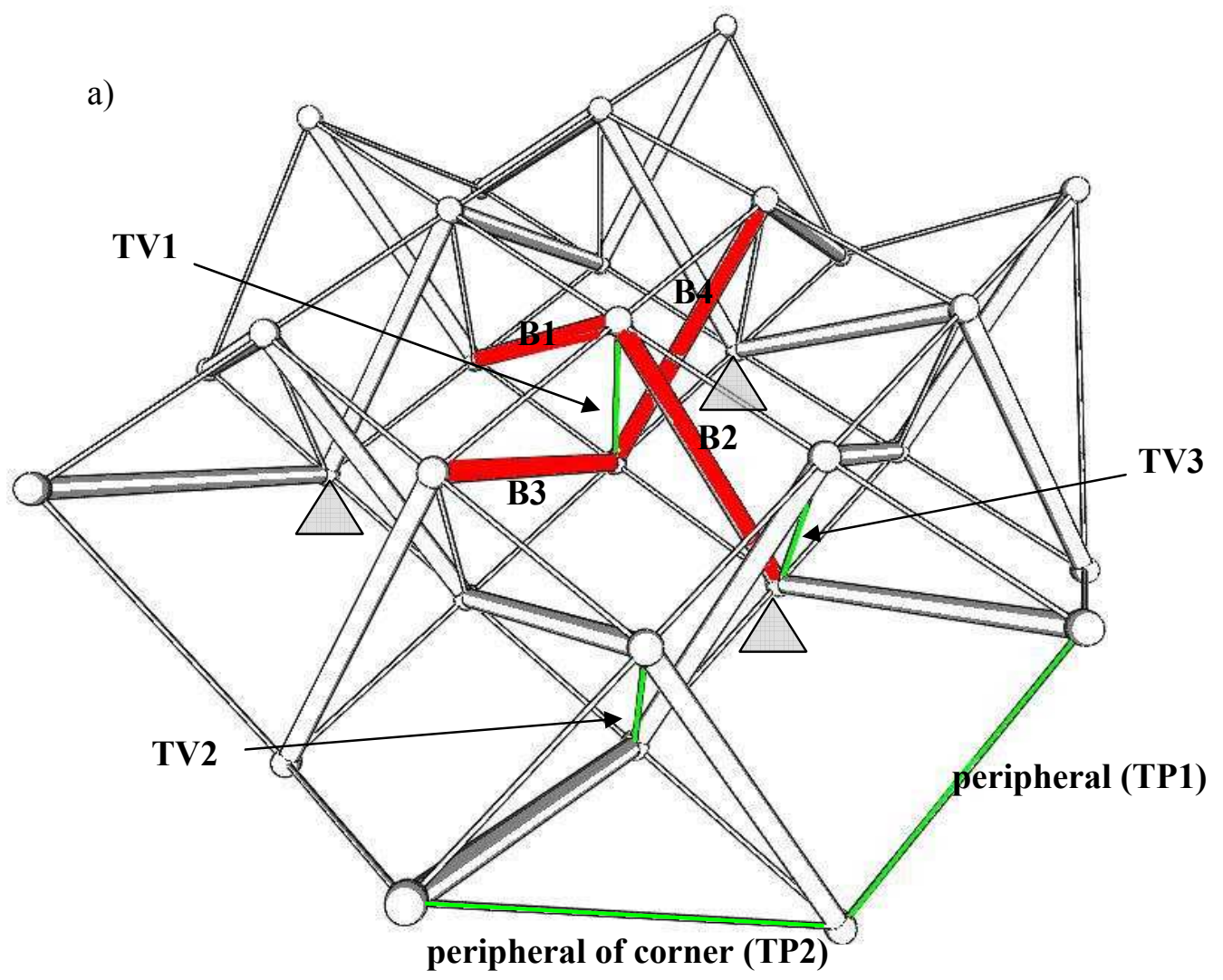

b)

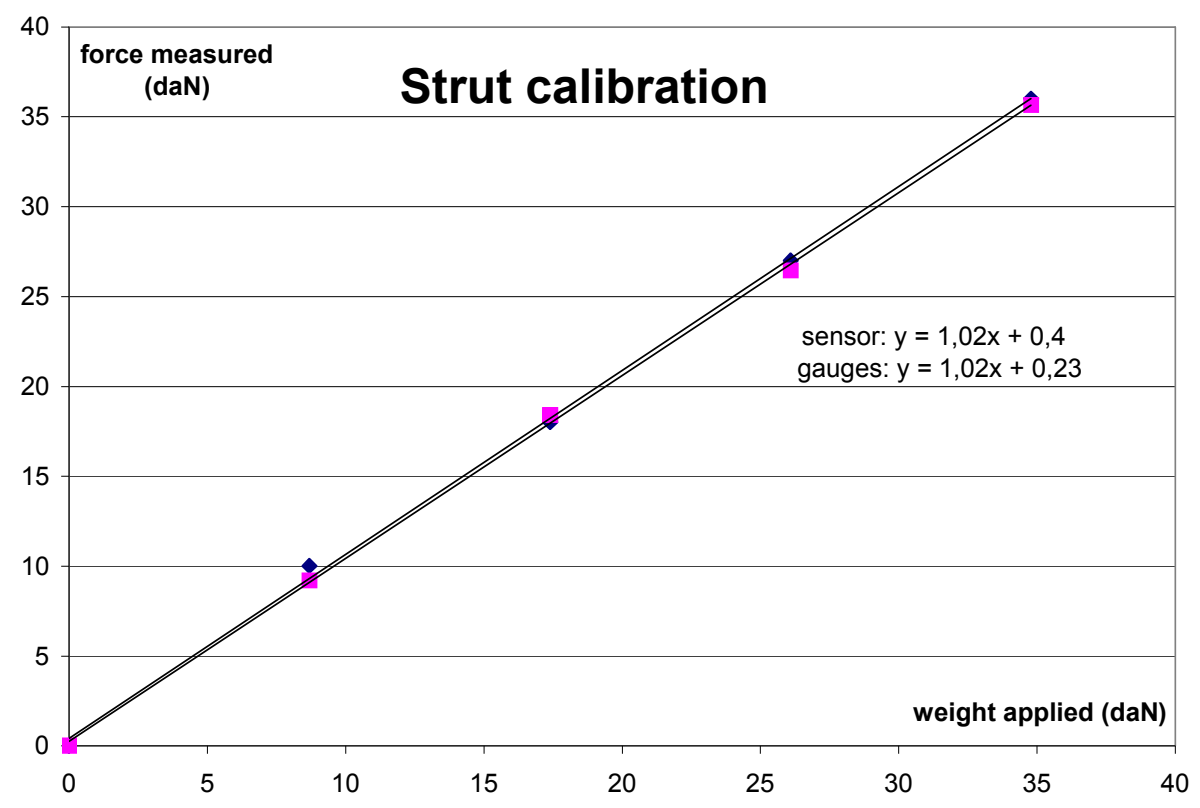

Figure 5. a) Location of the instrumented components in the mini grid - b) Calibration of complete half-bridge strain gauge for a strut. 


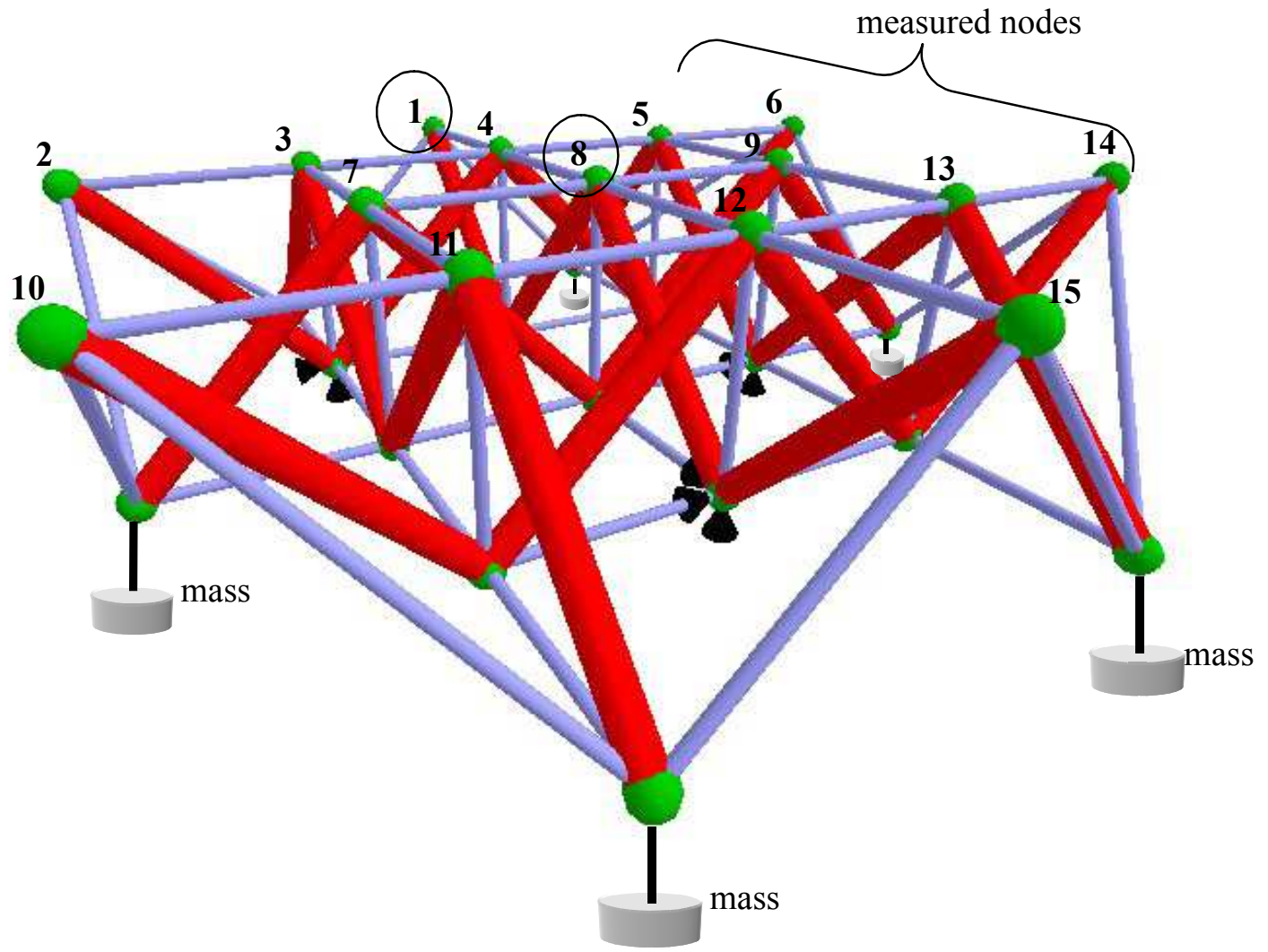

Figure 6. Visualization of the loading and the measured nodes. 
a)

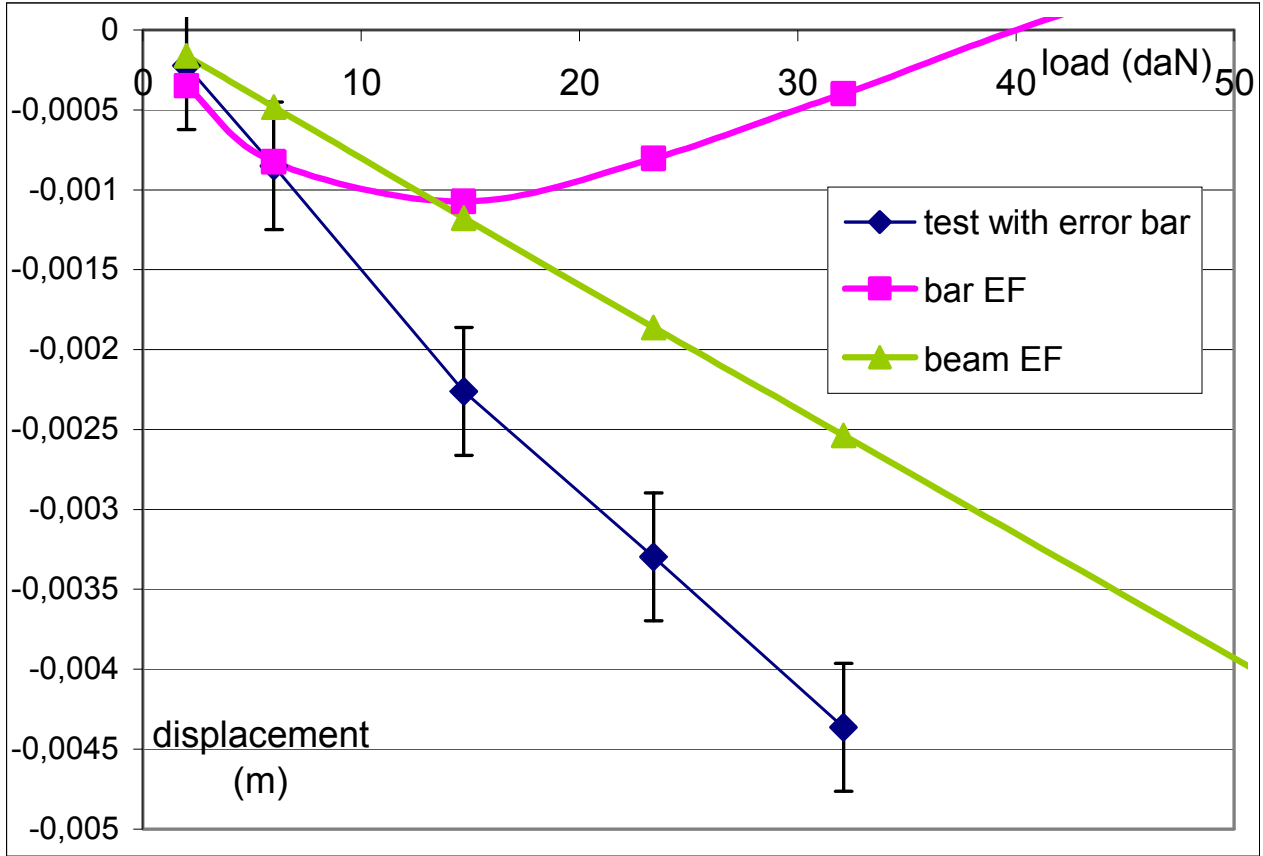

b)

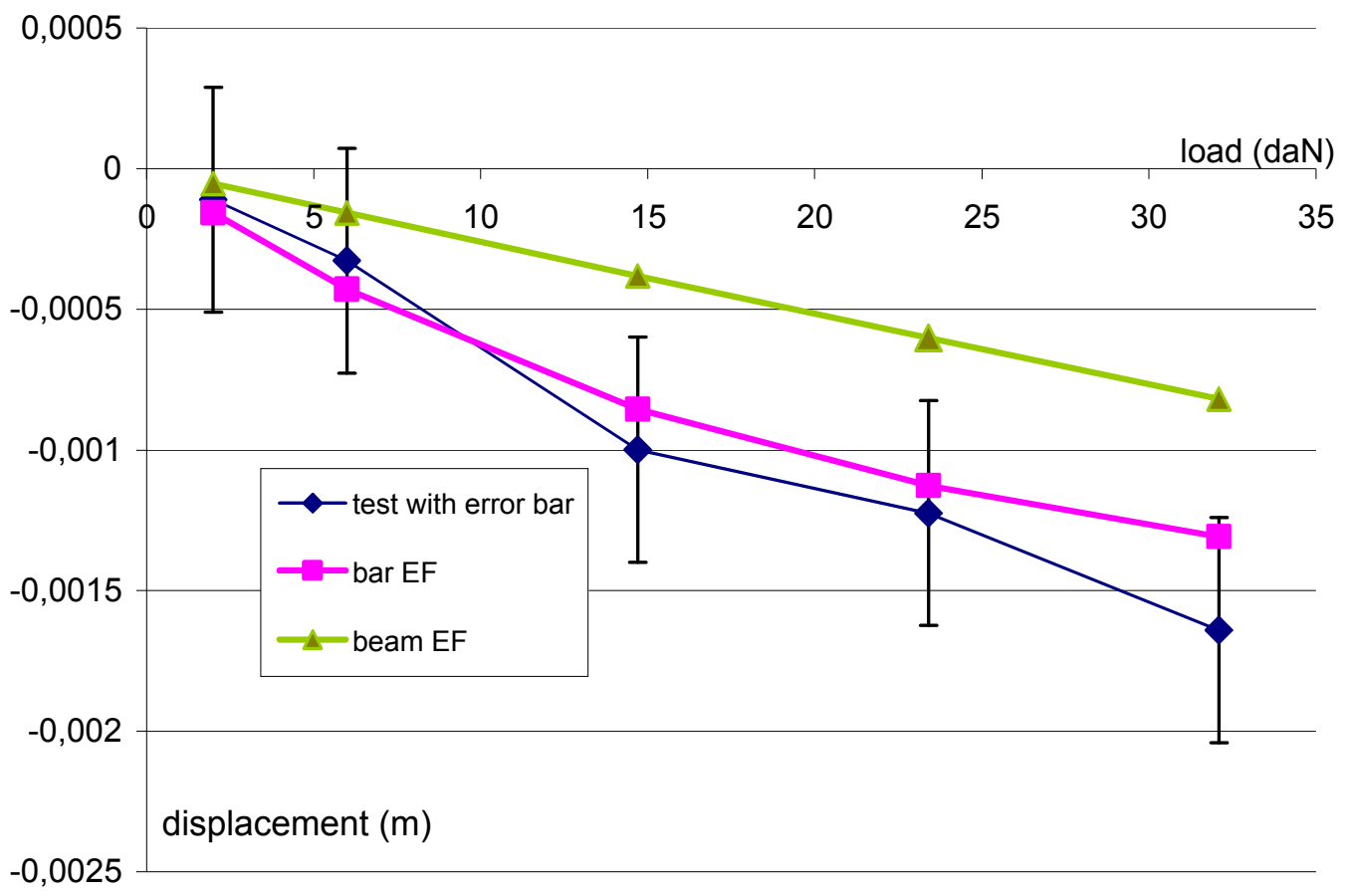

Figure 7. a) displacement evolution for the node 1 of the mini grid (peripheral), b) displacement evolution for the node 8 of the mini grid (central). 
a)

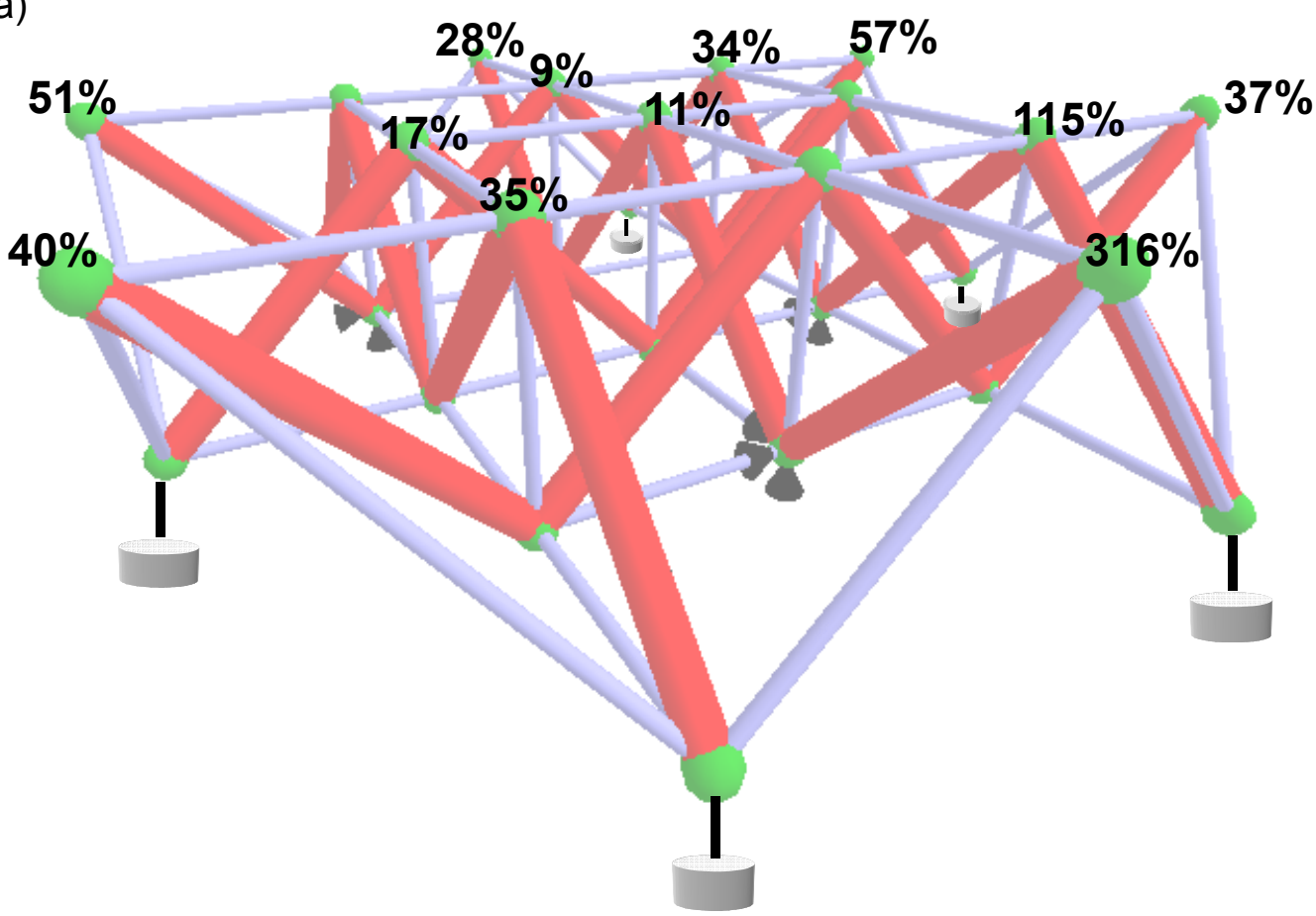

b)

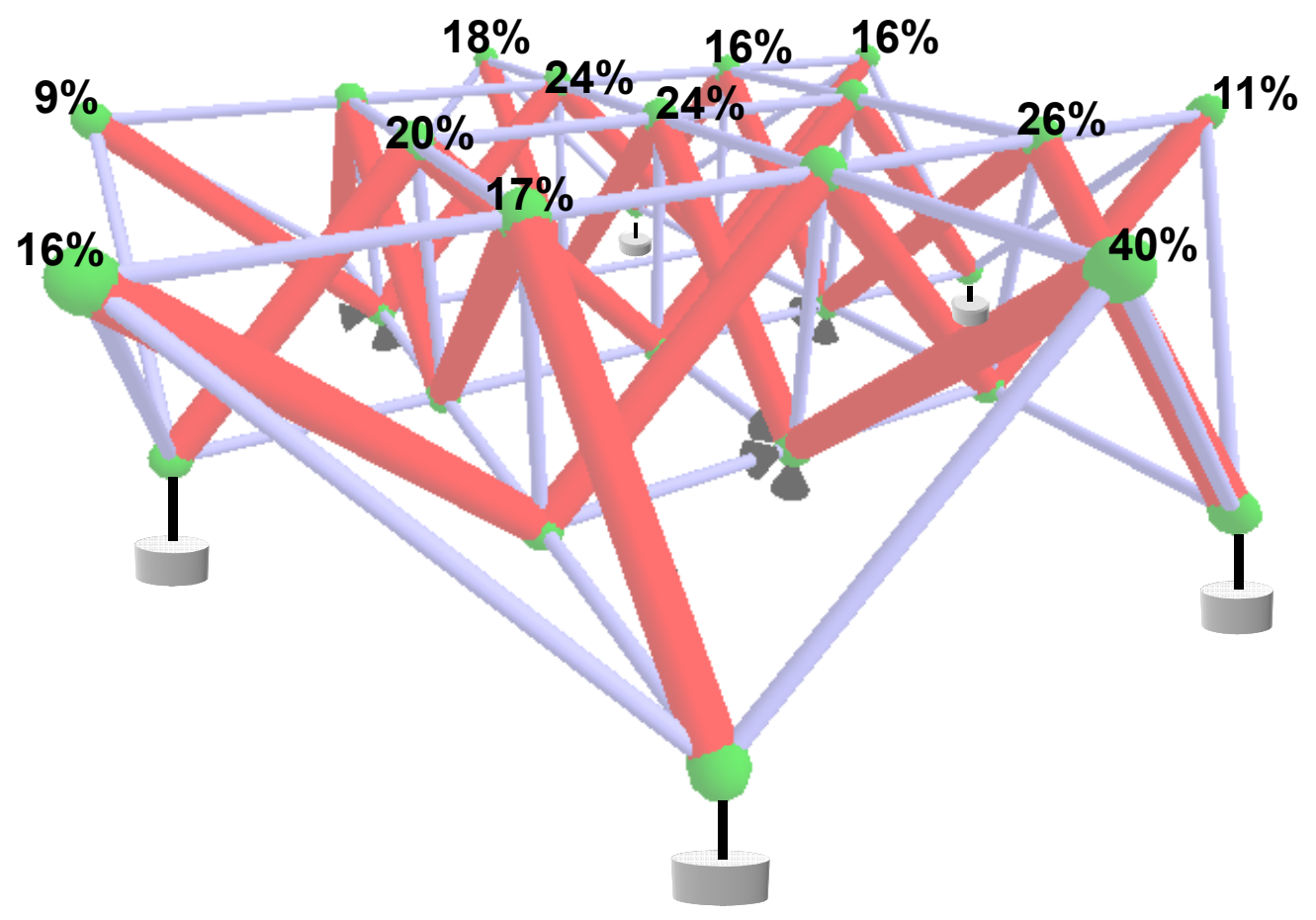

Figure 8. Displacement error, a) with structural bar element, b) with structural beam element for the struts. 


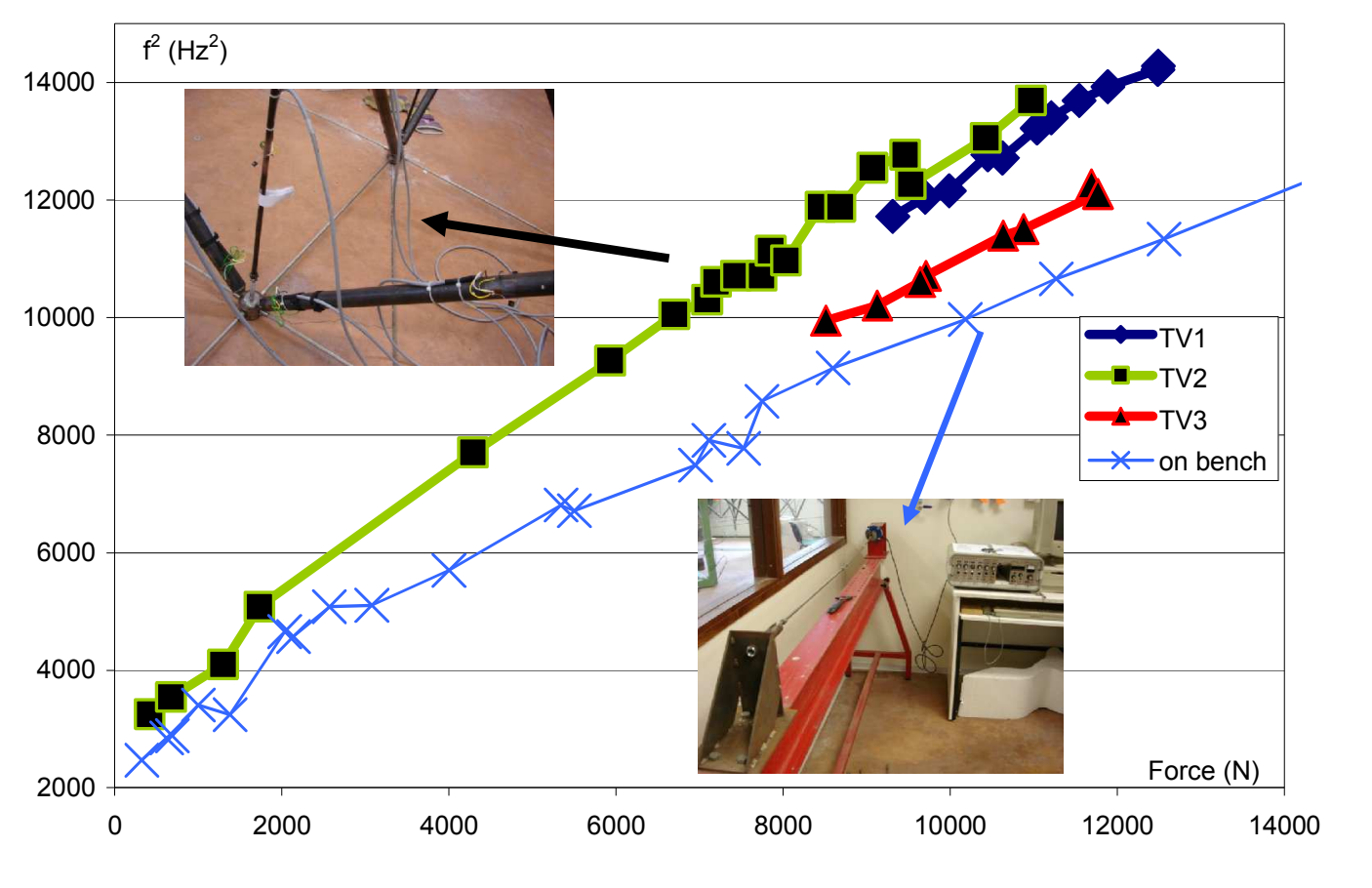

Figure 9

Figre

Figure 9
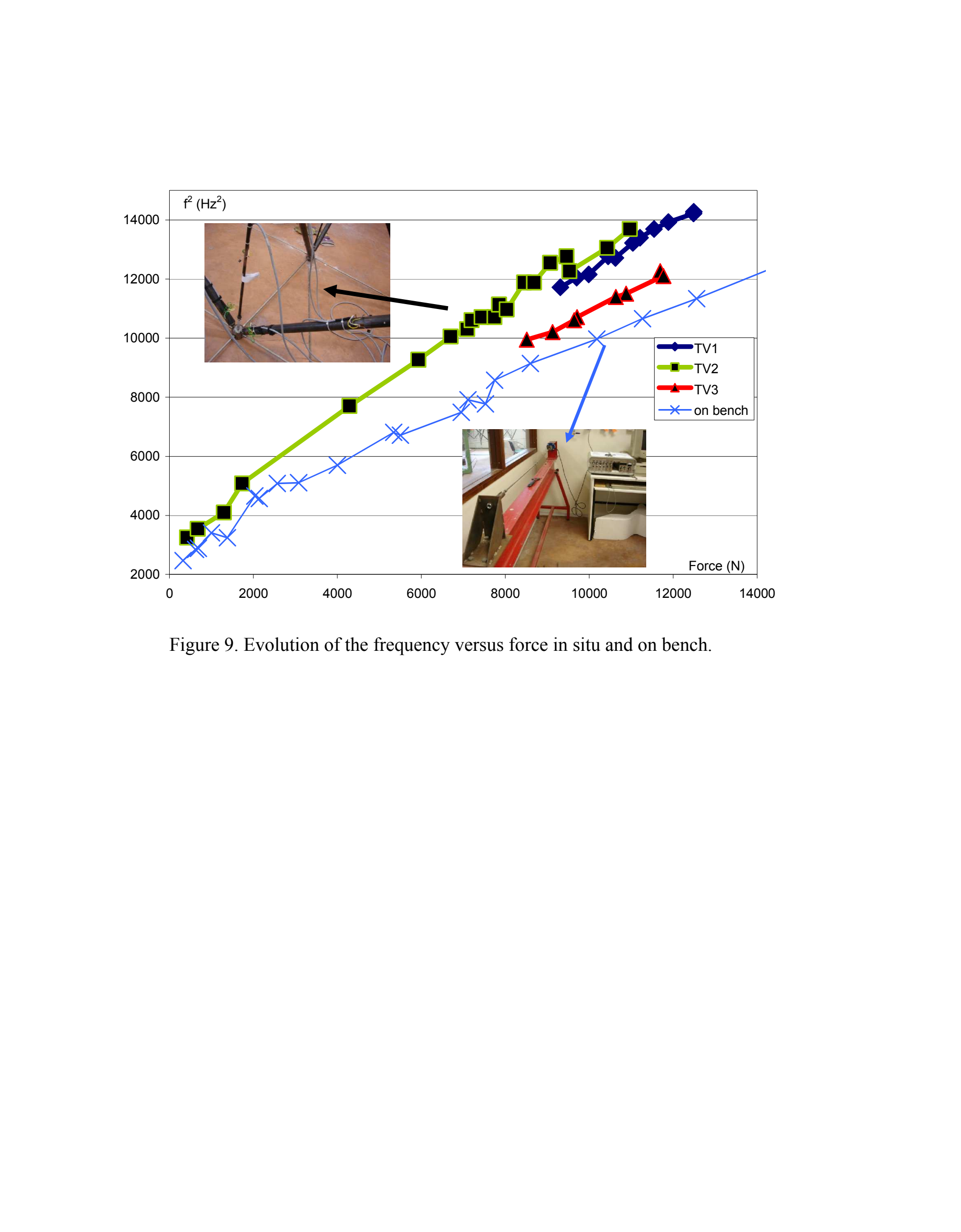
a)

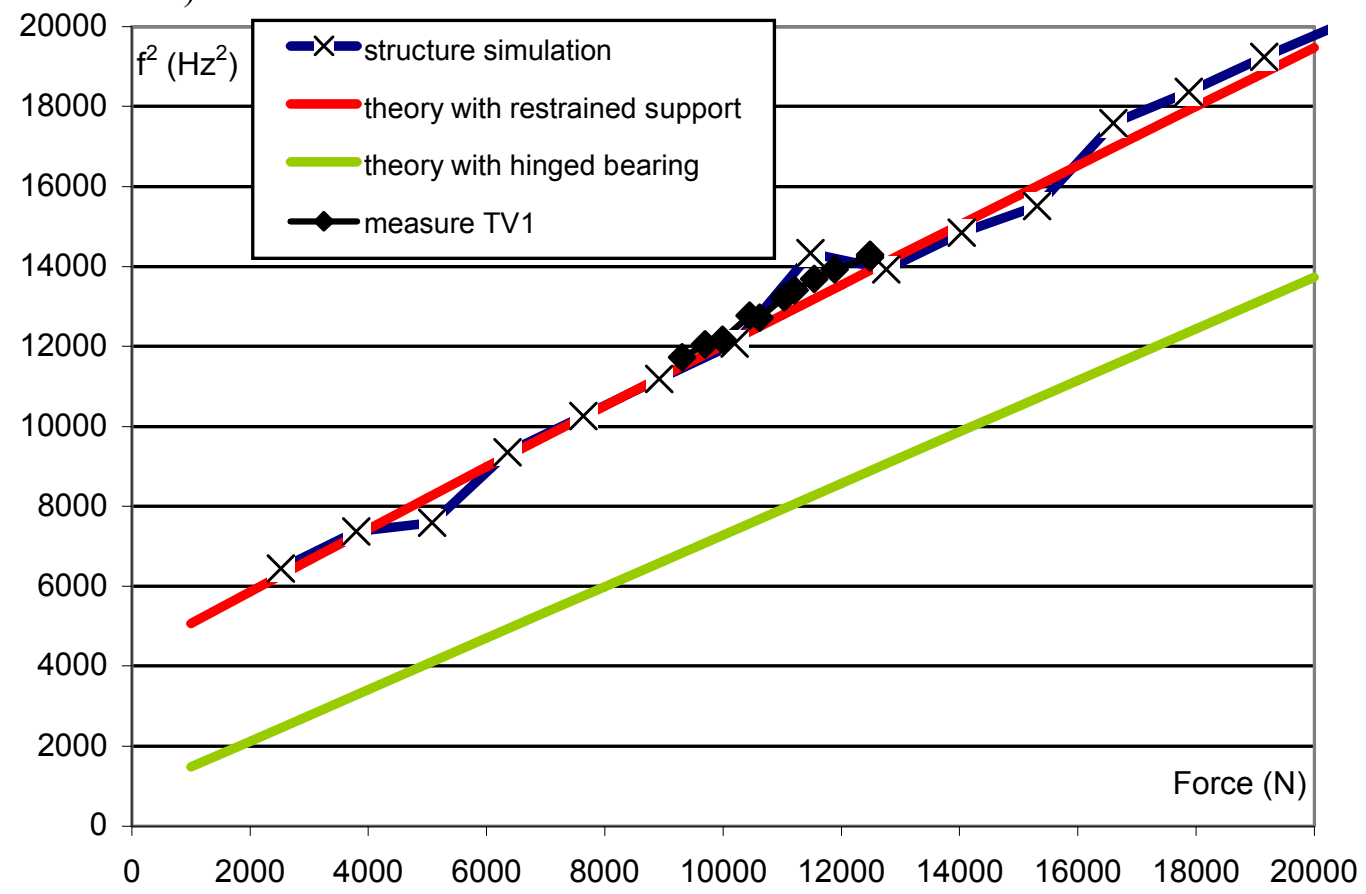

b)

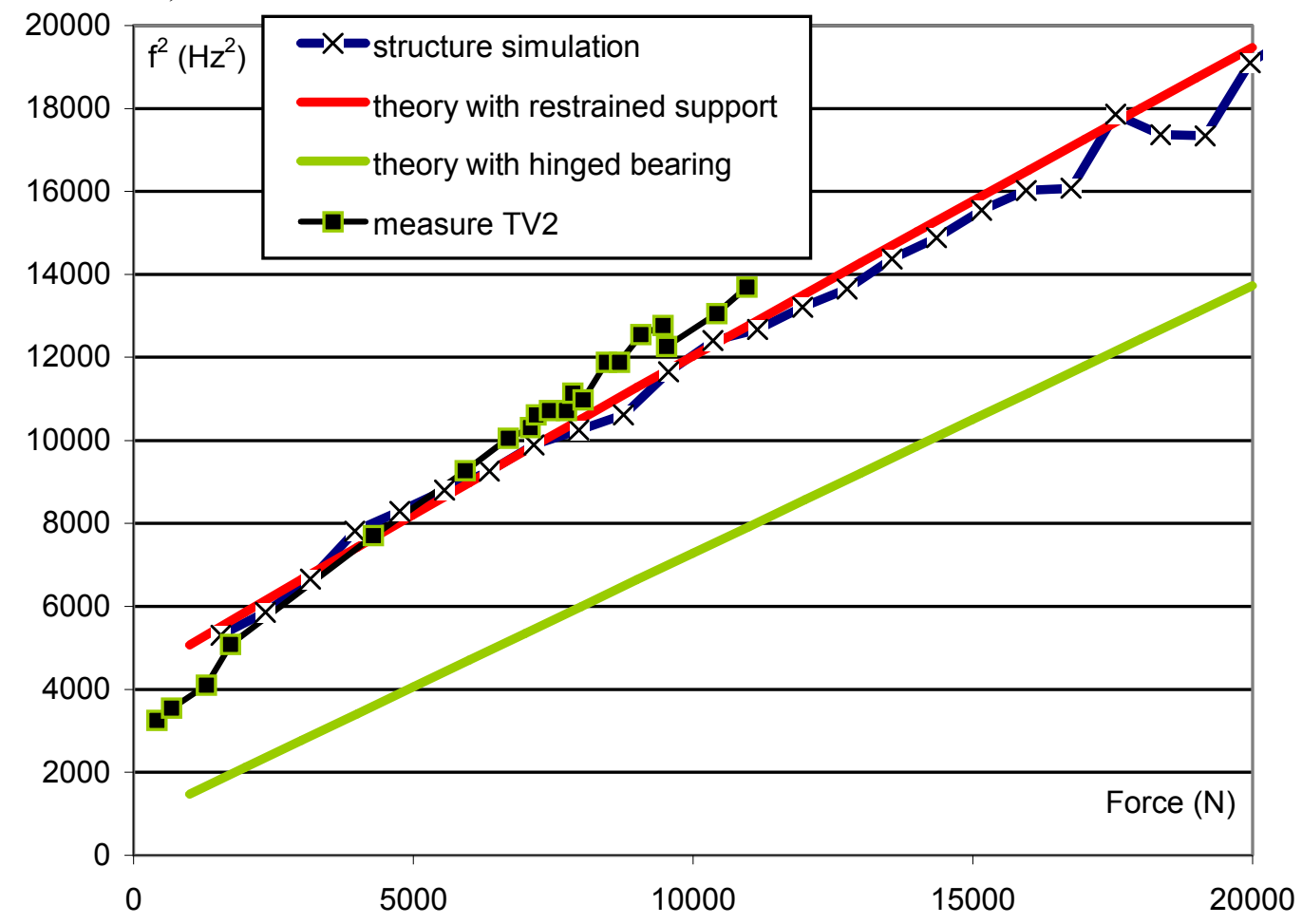




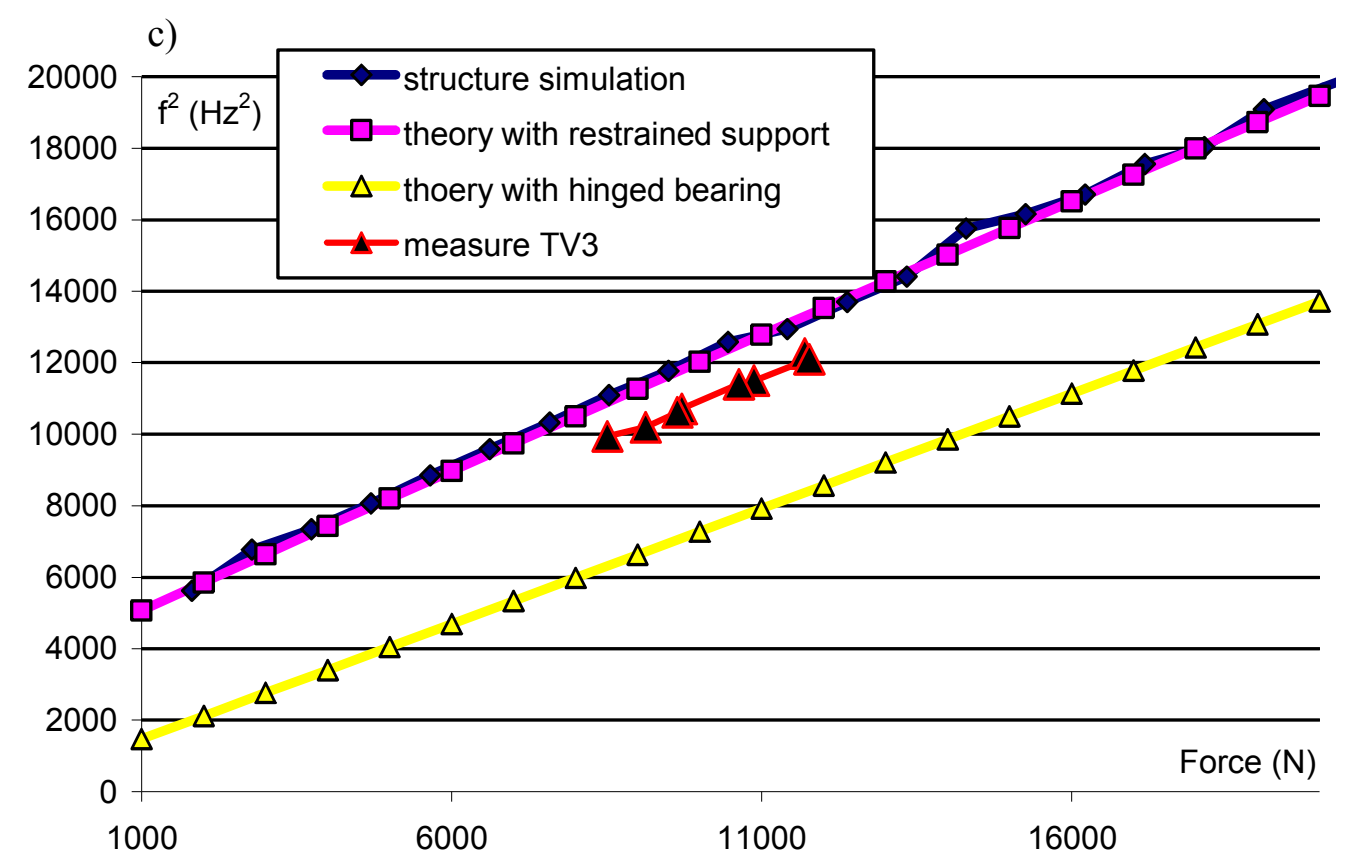

Figure 10. $1^{\text {st }}$ eigen frequency evolution for a) the TV1 tie, b) the TV2 tie, c) the TV3 tie. 
a)

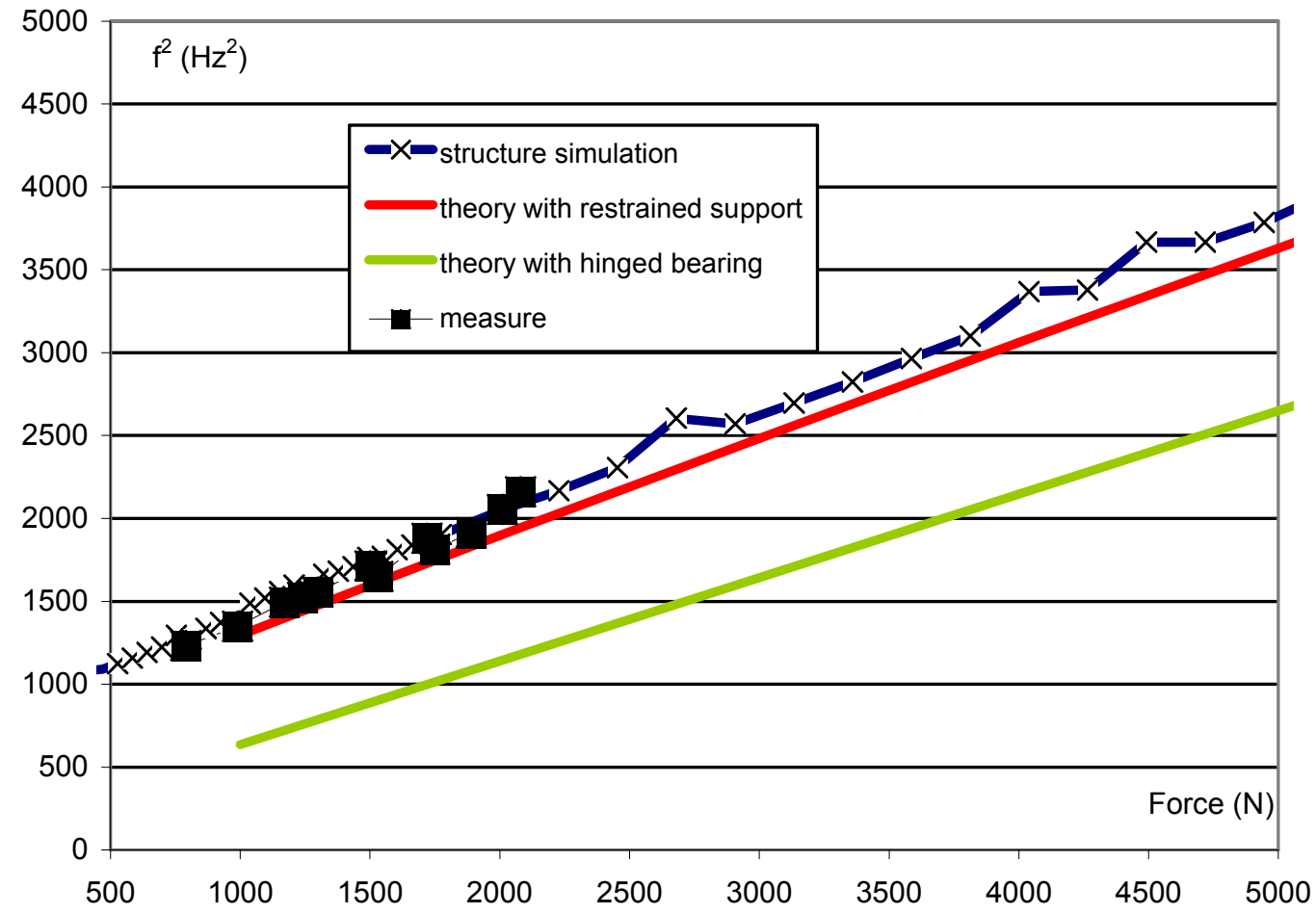

b)

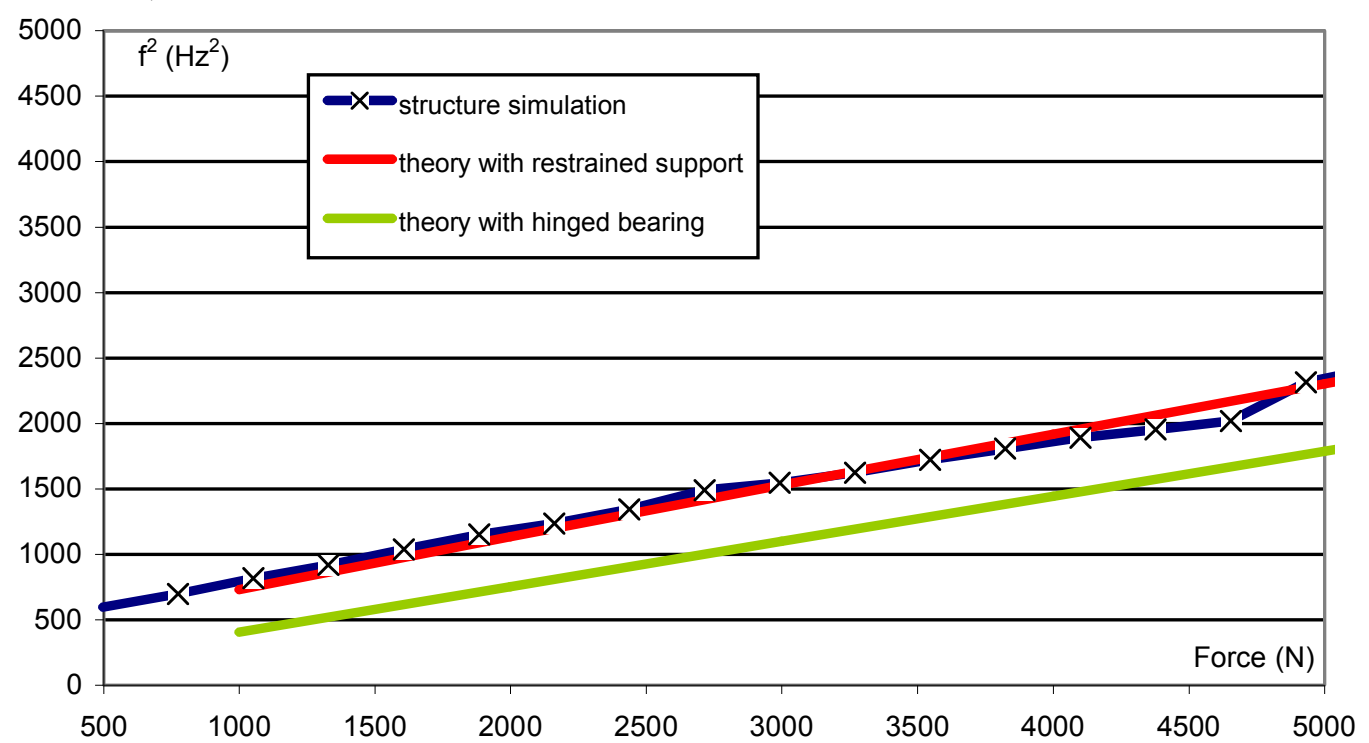

Figure $11.1^{\text {st }}$ eigen frequency evolution a) for peripheral tie, b) for peripheral corner tie without measure. 


\begin{tabular}{|c|c|c|c|c|c|}
\hline Component & Length (m) & $\begin{array}{c}\text { Young's Modulus } \\
(\mathrm{MPa})\end{array}$ & $\begin{array}{c}\text { Section } \\
\left(\mathrm{cm}^{2}\right)\end{array}$ & $\begin{array}{c}\text { Inertia } \\
\left(\mathrm{cm}^{4}\right)\end{array}$ & $\begin{array}{c}\text { Density } \\
\left(\mathrm{kg} / \mathrm{m}^{3}\right)\end{array}$ \\
\hline Struts & 1.13 & $2.010^{6}$ & 3.30 & 1.80 & 7800 \\
\hline Cables & 0.80 & $1.610^{6}$ & 0.503 & 0.0201 & 7157 \\
\hline Vertical ties & 0.80 & $1.710^{6}$ & 0.785 & 0.0491 & 7720 \\
\hline Side/Corner ties & $1.13 / 1.38$ & $2.010^{6}$ & 0.503 & 0.0201 & 7500 \\
\hline
\end{tabular}

Table 1. Characteristics of the mini grid components. 


\begin{tabular}{|c|c|c|}
\hline Component & $\begin{array}{c}\text { Strain } \\
(\mathrm{daN})\end{array}$ & Compensation (daN difference) \\
\hline Vertical Tie & -1144 & $\frac{821+804}{\sqrt{2}}-1144=5$ \\
\hline Strut 1 & 821 & $\frac{821-804}{\sqrt{2}}-98+88=2$ \\
\hline Strut 2 & 804 & -98 \\
\hline Cable 1 & -88 & $491-438=53$ \\
\hline Cable 2 & -438 & \\
\hline Cable 3 & -491 & \\
\hline Cable 4 & \\
\hline
\end{tabular}

Table 2. Node compensation. 